\title{
DRONOVI U POLJOPRIVREDI - IT PODRŠKA, ZAKONSKE REGULATIVE I PREDNOSTI UPOTREBE
}

\author{
Slaviša llić1, *, \\ Žaklina Spalević1, \\ Miloš llić ${ }^{2}$ \\ 'Univerzitet Singidunum, \\ Beograd, Srbija \\ ${ }^{2}$ Fakultet tehničkih nauka, \\ Univerzitet u Prištini sa privremenim \\ sedištem u Kosovskoj Mitrovici, Srbija
}

\begin{abstract}
Rezime:
Ubrzani razvoj i sve veća popularnost bespilotnih letelica (dronova), kao i prednosti njihove upotrebe otvorili su mogućnosti za njihovom primenom u poljoprivredi. Hardverska i softverska rešenja koje koriste dronovi novijih generacija se razvijaju velikom brzinom. U cilju unapređenja poljoprivredne proizvodnje sve je značajnija upotreba dronova različitih kategorija i namena. Upotreba dronova u poljoprivredi ogleda se kako u prikupljanju podataka sa terena o zdravstvenom stanju biljaka, tako i u primeni u procesu zaprašivanja, uzorkovanja zemljišta i prihrani biljaka. Svaka bespilotna letelica u zavisnosti od svoje namene odlikuje se specifičnom hardverskom opremom i softverskim funkcionalnostima koje obezbeđuju njeno korišćenje. Svaka upotreba dronova praćena je setom zakonskih regulativa kojih je korisnik letelice dužan da se pridržava. Cilj ovog rada je poređenje različitih tipova dronova dostupnih za korišćenje u poljoprivredi. Pregled i poređenje oblasti primene poljoprivrednih dronova dat je sa aspekta implementiranih hardverskih i softverskih rešenja, prednosti i nedostataka korišćenja, kao i zakonskih normi kojima je regulisana ova oblast.
\end{abstract}

Ključne reči:

DJI, NDVI indeks, zaprašivanje, kategorije dronova.

\section{UVOD}

Razvoj informaciono komunikacionih tehnologija (ICT) posebno $\mathrm{u}$ oblasti kreiranja i obrade velikih skupova podataka, intenzivno doprinosi kreiranju sistema i softverskih rešenja primenljivih u svakodnevnom životu i radu ljudi. Jedna od novijih oblasti primene informaciono komunikacionih tehnologija jeste njihova primena u oblasti poljoprivredne proizvodnje i proizvodnje hrane. Primena ICT resursa na rešavanje problema i unapređenje procesa poljoprivredne proizvodnje doživljava veliku ekspanziju poslednjih nekoliko godina. Koncept primene ICT tehnologija u poljoprivredi poznat je kao precizna poljoprivreda ili epoljoprivreda. Precizna poljoprivreda predstavlja proces poljoprivredne proizvodnje koji uključuje primenu informacionih tehnologija, satelitske navigacije, primenu različitih vrsta senzora, praćenje radnih mašina, kao i analizu prikupljenih podataka i proces donošenja odluka [1].
Odgovorno lice:

Slaviša Ilić

e-pošta:

islave@live.com 
Jedna od tehnika koja se sve češće primenjuje u novije vreme jeste snimanje proizvodnih poljoprivrednih površina iz vazduha [2]. Korišćenjem bespilotnih letelica vrši se prikupljanje potrebnih informacija baziranih na seriji fotografija i snimaka površina na kojima se vrši uzgoj poljoprivrednih proizvoda. U grupu letelica za prikupljanje potrebnih snimaka ubrajaju se sateliti, avioni, baloni, kao i sve popularniji mali dronovi. Posmatrano iz ugla funkcionalnosti i ekonomskih izdataka, korišćenje satelita i aviona zahteva određeno vremensko trajanje, sprovođenje odgovarajuće procedure kao i ekonomsku naknadu za svaki od načinjenih letova. Ovako organizovani letovi za potrebe snimanja proizvodnih površina ne mogu se ponavljati iznova i iznova. Praktično, primenom aviona i satelita nije moguće ponavljanje leta nad istom površinom više puta u toku dana.

U poređenju sa upotrebom satelita i aviona, dronovi nude mehanizam rada koji je značajno jednostavniji. Pored jednostavnosti upotrebe još jedna od prednosti kojom se dronovi izdvajaju jeste i opremljenost velikim brojem senzora različite namene i funkcionalnosti. Neki od senzora kojima su dronovi opremljeni su optički senzori, infrared senzori, senzori za radio detekciju, nivelaciju, pozicioniranje i izbegavanje prepreka itd. Pored senzora, dronovi su opremljeni različitim tipovima kamera. Neke od kamera koje se mogu naći kao standardna ili dodatna oprema dronova su kamere za snimanje RGB spektra, NIR, RE, MultiSpec i ThermoMap kamere. Upotrebom dronova otklanja se glavni nedostatak upotrebe satelita i aviona, a to je ponovna i višestruka upotreba za snimanje konkretne proizvodne poljoprivredne površine. Pritom, ponavljanje procesa snimanja upotrebom dronova dobija se po znatno nižoj ceni [3].

Dronove karakterišu i male dimenzije, laka prenosivost sa jedne lokacije na drugu, kao i mogućnost brzog i jednostavnog sklapanja na konkretnoj lokaciji. Takođe, karakteriše ih i brza upotreba, i za razliku od ostalih bespilotnih letelica mali prostor na zemlji za potrebe poletanja i sletanja. Bez obzira na činjenicu da upotreba dronova zauzima značajnije mesto u poslednjih nekoliko godina, dronovi su zvanično u komercijalnoj upotrebi prisutni još od 1980. godine. Neke od oblasti primene dronova u poljoprivredi su zasnovane na obradi fotografija načinjenih ovim letelicama i dobijanju značajne količine informacija o stanju useva na poljoprivrednim površinama. Takođe, oni se koriste i za potrebe obavljanja određenih poljoprivrednih procesa kao što su hemijska zaštita, setva i prihrana.

\section{OBLASTI UPOTREBE DRONOVA U POLJOPRIVREDI}

Zahvaljujući prednostima kojima se odlikuje, praktična primena dronova u različim oblastima privrede $\mathrm{i}$ industrije je sve više zastupljena i beleži značajnu ekspanziju u razvoju. Uz automatizaciju poljoprivredne proizvodnje primenom novih tehnologija, prepoznaje se i upotreba dronova za dalja unapređenja. Neke od mogućnosti primene dronova u okviru poljoprivredne proizvodnje uključuju: praćenje stanja useva i mapiranje proizvodnih površina, klasifikaciju biljaka na proizvodnim površinama, praćenje pojave bolesti i štetočina, detekciju površina na kojima je došlo do pojave stresa kod biljaka usled prevelike količine vode ili prisustva drugih faktora, detekciju površina na kojima je potrebno izvršiti zalivanje ili odvodnjavanje, procenu biomase biljaka, kao i monitoring korovskih zajednica prisutnih na proizvodnim površinama [4].

Praćenje stanja useva na proizvodnim površinama predstavlja jednu od redovnih aktivnosti u poljoprivrednoj proizvodnji. Izazovi praćenja stanja useva povećavaju se usled sve prisutnijih klimatskih promena, i nepredvidivih vremenskih uslova. Tradicionalno posmatranje gajenih biljaka posebno useva na proizvodnim površinama obavlja se odlaskom i obilaskom istih. Ukoliko se radi o velikim proizvodnim površinama, kao i ukoliko se radi o njihovoj razruđenosti na veći broj lokacija, obilazak zahteva izvesno utrošeno vreme. $U$ isto vreme nepovoljni vremenski uslovi mogu odložiti obilazak proizvodnih površina i time onemogućiti blagovremenu detekciju potencijalnih problema u proizvodnji. Upotreba dronova opremljenih odgovarajućim setom senzora nudi poljoprivrednim proizvođačima mogućnosti praćenja i nadgledanja proizvodnih površina svakoga dana bez obzira na veličinu parcela i vremenske uslove. $\mathrm{Na}$ primer, pomoću drona se može obaviti let iznad celokupne proizvodne površine za svega nekoliko minuta. $\mathrm{Na}$ osnovu načinjenih fotografija tokom ovakvog leta poljoprivredni proizvođač dobija tačne informacije o stanju useva [5]. Pritom, eliminisan je tradicionalni obilazak cele parcele, što značajno redukuje utrošeno vreme. Obrada kreiranih fotografija i evidentiranih prostorno vremenskih podataka primenom kompijuterske vizije i data mining metoda, mogu se kreirati modeli preciznog razvoja useva. Takođe, adekvatnom obradom prikupljenih podataka mogu se detektovati neefikasnosti proizvodnje, što omogućava blagovremeno reagovanje i upravljanje usevima. 
Dronovi opremljeni hiperspektralnim, multispektralnim ili termalnim senzorima pogodni su za korišćenje u domenu detektovanja na kom delu proizvodne površine se javlja nedostatak vlage, kao i eventualno prisustvo veće količine vode. Nedostatak vlage u zemljištu kao i veće prisustvo vode mogu uzrokovati stres kod biljaka, kao i probleme sa normalnim fiziološkim razvićem. Na ovakav način se vrši blagovremeno detektovanje delova proizvodnih površina na kojima je potrebno obaviti navodnjavanje ili pak odvodnjavanje. Dodatno, nakon nicanja biljaka, a u toku procesa rasta, korišćenje dronova omogućava izračunavanje vegetativnog indeksa [2]. Vegatativni indeks opisuje relativnu gustinu nicanja useva i njegovo zdravstveno stanje. Takođe, na osnovu vegetativnog indeksa može se odrediti količina energije ili toplote koju kultura emituje. Svi navedeni parametri koriste se u procesu procene fiziološkog stanja biljaka. Dobijeni podatak o gustini nicanja biljaka nosi u sebi informaciju o tome na kojim delovima površine je potrebno izvršiti prihranu kojom količinom đubriva, kao i o prvim procenama očekivanog prinosa.

Procena zdravstvenog stanja biljaka od velike je važnosti u pogledu blagovremenog detektovanja pojave bolesti i štetočina i njhovog adekvatnog suzbijanja. Upotrebom dronova opremljenih za snimanje proizvodnih površina korišćenjem vidljivog i infrared (NIR) dela spektra, može se detektovati koje biljke reflektuju različitu količinu zelene svetlosti i NIR svetlosti, a uz procenu vlažnosti zemljišta, dobijaju se multispektralne slike proizvodnih površina kojima se prate promene na biljkama kao indikatori njihovog zdravstvenog stanja. Aktivno praćenje omogućava brzo reagovanje u slučaju detekcije pojave bolesti što može povećati sposobnost biljaka da se izbore sa bolestima. Ukoliko pak usled pojave bolesti dođe do propadanja biljaka, načinjeni snimci kao i podaci dobijeni na osnovu ovih snimaka mogu poslužiti kao dokaz kod osiguravajućih kompanija. Primena u praksi pokazuje da su dronovi veoma korisni kada se radi o davanju tačne procene u gubicima na proizvodnim površinama prouzrokovanim kako pojavom bolesti i štetočina, tako i vremenskim nepogodama u vidu grada i mraza. Praktično, ovakvi podaci dobijeni snimanjem konkretnih površina predstavljaju digitalne dokaze [6].

Mapiranje proizvodnih površina u cilju evidencije zasejanih biljnih kultura može se obaviti upotrebom dronova. $\mathrm{U}$ isto vreme pored evidencija o biljnim kulturama zasejanim na konkretnim površinama, na osnovu načinjenih snimaka može se izvršiti i monitoring korovskih zajednica prisutnih na datim površinama. Na ovakav način se eliminiše potreba za hemijskim tretmanima nad celim površinama, već se tretman može vršiti samo nad površinama na kojima je evidentirano prisustvo korovskih zajednica.

Nabrojane mogućnosti primene dronova zasnivaju se na obradi fotografija i video zapisa dobijenih preletom iznad proizvodnih površina. Let iznad proizvodnih površina obavlja se prema unapred definisanim putanjama. Odgovornost za praćenje putanja i kontrolisanje leta može biti dvostruko regulisna. Jedan od vidova moguće realizacije jeste kontrolisanje leta letelice od strane lica sa zemlje, dok drugi način predstavlja autonomni let letelice korišćenjem sistema za pozicioniranje. Ostvareni cilj se ogleda u uspešnom snimanju celokupne proizvodne površine praćenjem unapred zadatih putanja, kako ne bi došlo do izostavljanja nekog dela površine.

Pored primene dronova u domenu kreiranja fotografija i video zapisa proizvodnih površina, sve češća primena ovih tipova letelica ogleda se u: vršenju hemijske zaštite biljaka, analizi zemljišta, kao i obavljaju setve biljaka. Pored bespilotnih letelica poznatih kao dronovi, u ovu kategoriju se takođe ubrajaju i bespilotni helikopteri.

Upotreba dronova u oblasti hemijske zaštite biljaka ogleda se u snimanju površine pod gajenim biljkama i donošenju odluke na kojim delovima površine je potrebno uraditi hemijsku zaštitu. Nakon donošenja odluke, korišćenjem adekvatne opreme, dron može podesiti svoju visinu i položaj u odnosu na površinu zemlje i izvršiti hemijsku zaštitu prskanjem odgovarajuće količine hemijskog preparata. Prednost upotrebe ovakvog načina hemijske zaštite ogleda se u efikasnoj hemijskoj zaštiti $\mathrm{u}$ realnom vremenu, uz minimalni utrošak vremena i redukciju utrošene količine hemijskih sredstava.

$\mathrm{Na}$ ovakav način se vodi računa o zaštiti životne sredine i posebno se umanjuje mogućnost zagađenja podzemnih voda. Stručnjaci procenjuju da poljoprivredni dronovi mogu obaviti hemijsku zaštitu zaprašivanjem do četrdeset puta brže nego što je to slučaj sa tradicionalnim zaprašivačima. Pritom, upotrebom dronova za potrebe hemijske zaštite može se uštedeti do $90 \%$ vode, kao i od 30\% do $40 \%$ pesticida. Samim tim mali dijametar pokrivenosti doprinosi boljoj pokrivenosti površine, kao i uspešnijoj zaštiti. Svakako neizostavna je i činjenica da u procesu zaštite nema direktne aktivnosti čoveka. Praktično, lice koje upravlja dronom nalazi se na bezbednoj udaljenosti od površine koja se zaprašuje, tako da se znatno redukuje uticaj pesticida na čoveka.

Pored hemijske zaštite dronovi su takođe u upotrebi i kada se radi o analizi zemljišta. Njihovom upotrebom vrši se mapiranje zemljišta u skladu sa količinom hranljivih materija u zemljištu. Ovakva informacija otvara 
mogućnosti analize zemljišta u domenu određivanja kultura koje je moguće posejati na konkretnoj površini. Takođe, nakon sejanja, analiza zemljišta obavljena drnovima obezbeđuje podatke za potrebe prihrane i navodnjavanja gajenih biljaka. Praktično, na osnovu uzoraka zemljišta i analize zemljišta moguće je odrediti koji delovi su podložniji isparenju, a samim tim se na datim površinama javlja veća potreba za navodnjavanjem.

Setva gajenih biljaka predstavlja jednu od složenih i vremenski zahtevnih poljoprivrednih procesa. Upotreba dronova za potrebe setve dostigla je stopu uspešnosti od 70\%. Pritom, upotrebom dronova dolazi do smanjenja troškova setve čak do $85 \%$. Praktično, setva se obavlja tako što dronovi ispaljuju mahune sa semenom i biljnim hranivom u zemlju, obezbeđujući na taj način biljci sve hranljive sastojke potrebne za osnovne životne potrebe.

\section{KATEGORIZACIJA DRONOVA}

Unapređenje procesa poljoprivredne proizvodnje može se obaviti korišćenjem dva tipa bespilotnih letelica ili dronova. Jedan od tipova predstavljaju dronovi sa fiksnim krilima, dok drugi od tipova predstavljaju kvadkopteri ili takozvani multi rotor dronovi. Jedni i drugi se odlikuju različitim setom opreme, različitim načinom rada, pa samim tim i različitom namenom. Osnovne razlike između ova dva tipa dronova ogledaju se najpre u načinu poletanja i sletanja, brzini leta, kao i maksimalnom vremenskom trajanju leta. Dronovi sa fiksnim krilima najčešće poleću lansiranjem iz ruke korisnika, dok multirotor dronovi mogu poletati sa zemlje vertikalno naviše. Što se tiče procesa sletanja, dronovi sa fiksnim krilima za proces sletanja zahtevaju veću površinu na kojoj će se uz smanjenje visine spustiti po zemlji. Multi rotor dronovi sletanje obavljaju spuštanjem vertiklano naniže sve do nivoa zemlje, tako da im za sletanje ne treba više površine od one koju sami zauzimaju. Ukoliko se ove dve kategorije uporede po brzini i maksimalnom trajanju leta uočava se da dronovi sa fiksnim krilima ostvaruju manju maksimalnu brzinu letenja, ali pritom imaju veće maksimalno vreme leta, čime je obezbeđena veća površina koju ovi dronovi mogu pokriti. Multirotor dronovi karakterišu se i mogućnošću podizanja određenog tereta, čime je omogućena bolja opremljenost kamerama, kao i opremom za zaprašivanje i prihranu biljaka. Sa druge strane, dronovi sa fiksnim krilima nemaju mogućnost podizanja većeg tereta, pa je samim tim ograničena mogućnost njihovog dodatnog opremanja kamerama i potrebnim senzorima.
Jedan od predstavnika dronova sa fiksnim krilima je Sensefly eBee. Ovaj dron karakteriše se ekonomičnošću s obzirom na male dimenzije i kvalitetan sistem za snimanje. Osnovna verzija ovog drona obuhvata opremljenost infracrvenom kamerom. Takođe, kao dodatan vid opreme može se instalirati kamera za kreiranje 3D termalne mape prostora [7]. Putanja leta ovog drona može se odrediti korišćenjm računara sa zemlje. Praktično, letelica se putem kreiranog softvera dostupnog korisnicima povezuje sa računarom, čime je omogućeno podešavanje putanje pre početka leta ovog drona. Kreirani softver omogućava i menjanje prvobitne putanje tokom trajanja leta. Tokom jednog trajanja leta ovaj dron može preleteti između $22 \mathrm{~km}^{2}$ i $40 \mathrm{~km}^{2}$. Oblast pokrivenosti tokom jednog leta uslovljena je visinom leta i težinom opreme. Tehnički podaci pokazuju da maksimalno vreme leta iznosi 59 minuta, dok je rezolucija na tlu do $1 \mathrm{~cm}$ po pikselu [8].

Jedan od možda najpoznatijih predstavnika multi rotor dronova, komercijalno dostupan na tržištu i širokog spektra namene svakako je DJI Phantom 4 Pro. Ovaj dron se odlikuje velikom brzinom leta od maksimalnih $72 \mathrm{~km} / \mathrm{h}$. Pritom, velika brzina leta mu omogućava let pri velikoj udaljenosti od lica zaduženog za upravljanje letelicom. Maksimalna udaljenost između letelice i daljinskog upravljača je do $7 \mathrm{~km}$. Letelica je opremljena sa tri seta vizuelnih sistema koji imaju zadatak da u trodimenzionalnom prostoru mapiraju i vode računa na prepreke ispred, iza i ispod letelice, kako bi se izbegli sudari (detektuju se objekti udaljeni i do $30 \mathrm{~m}$ od drona). Osim ova tri seta sistema, sa obe strane Phantom 4 Pro nalaze se infracrveni sistemi za detekciju prepreka, koji mogu da primete strana tela na udaljenosti od 0.2 do $7 \mathrm{~m}$ od drona. Pored standardne funkcionalnosti za povratak do bazne stanice, ovaj model sadrži i takozvanu Landing Protection opciju koja vodi računa da prilikom sletanja letelica ne sleti na neravan teren ili u vodu. Ovaj dron opremljen je kamerom visoke rezolucije čime je obezbeđeno snimanje $4 \mathrm{~K}$ videa. Kvalitet videa uz metapodatke prikupljene ostalim senzorima daje velike mogućnosti u pogledu kreiranja mapa terena, klasifikacije biljaka kao i određivanja zdravstvenog stanja biljaka na osnovu NDVI indeksa [9].

Dron oznake M6E-X firme Bejing TT Aviation Technology jedan je od predstavnika multi rotor dronova namenjenih upotrebi u poljoprivredi za potrebe obavljanja hemijske zaštite i prihrane biljaka. Praktično, za pomenute namene koristi se jedna letelica, pri čemu se vrši montaža odgovarajućeg uređaja u zavisnosti od toga da li je potrebno vršiti hemijsku zaštitu ili prihranu 
biljaka. Zapremina kontejnera u koji se smeštaju pesticidi iznosi 10 litara. Pritom, maksimalno vreme leta sa punim kontejnerom iznosi 11 minuta, dok maksimalno vreme leta sa praznim kontejnerom iznosi 30 minuta. Maksimalna brzina leta iznosi $15 \mathrm{~m} / \mathrm{s}$, dok je maksimalna visina leta limitirana na $3500 \mathrm{~m}$. Prečnik dizne za raspršivanje preparata iznosi 60 - 180 $\mu \mathrm{m}$. Radna efikasnost ovog drona je 1,8 do 2,5 hektara / 10 min pri brzini zaprašivanja od 4,8 $-6 \mathrm{~m} / \mathrm{s}$ [10]. Ovakva primena omogućava efikasnu hemijsku zaštitu uz visok procenat zaštite korisnika.

\section{PRIMERI UPOTREBE DRONOVAU POLJOPRIVREDI}

Primeri upotrebe dronova u poljoprivredi sve su učestaliji. Tokom 2014. godine u Južnoj Africi korišćene su male bespilotne letelice za potrebe kreiranja snimaka vinograda i procene zdravstvenog stanja nakon svake prihrane organskim đubrivom. Najpre je pomoću dronova rađeno mapiranje površina na kojima je bilo potrebno primeniti prskanje organskim đubrivom. Nakon toga bi na osnovu kreiranih mapa bila vršena prihrana, a nakon prihrane rađeno je novo mapiranje. Ponavljanjem postupka mapiranja vršeno je poređenje dobijenih slika. Počevši od 2015. godine novi set zakona koji reguliše ovu oblast u Južnoj Africi stupio je na snagu. Prema novom setu zakona za svako lice koje upravlja dronovima zahteva se pilotska dozvola, licenca izdata od strane Ministarstva saobraćaja, kao i odobrenje za upotrebu svakog pojedinačnog drona.

Tokom 2016. godine u Indiji dronovi su korišćeni kako bi se odredilo koliko površina pod kafom je zasejano. Takođe, snimanjem proizvodnih površina dobijeni su podaci o tome kolika je gustina biljaka na posejanim površinama, a sve u cilju određivanja mogućeg očekivanog prinosa ove biljke. U istoj godini objavljen je pravilnik kojim se reguliše korišćenje dronova i ostalih bespilotnih letelica. Ovim pravilnikom predviđeno je da svaka bespilotna letelica mora da ima jednistveni registracioni broj. Takođe svaki od operatera mora da ima dozvolu za upravljanje letelicom, kao i osiguranje za svaku konkretnu letelicu koja leti na visini većoj od 120m.

U Japanu su dronovi korišćeni za potrebe hemijske zaštite. Tokom jednog ciklusa zaštite bilo je više od dva miliona časova leta. Težina korišćenog drona iznosila je 94kg. Hemijska zaštita obavljana je korišćenjem principa unapred definisane putanje i GPS navigaciong sistema. Na teritoriji Japana 2015. godine stupila su na snagu nova pravila za korišćenje dronova. Prema ovim pravilima, dozvola za upravljanje dronom potrebna je samo u slučaju kada je visina leta veća od $150 \mathrm{~m}$ iznad zemlje, u blizini aerodroma ili iznad gusto naseljenih mesta. U suprotom, let se mora obavljati danju, na minimalnoj daljini od $30 \mathrm{~m}$ van prostora gde se okuplja veći broj ljudi.

\section{PRAVNE REGULATIVE PRIMENE DRONOVA}

Upotreba dronova kako u komercijalne svrhe, tako i domenu poljoprivrede, regulisana je vazduhoplovnim propisima. Vazduhoplovni propisi u pogledu upotrebe dronova razlikuju se u zavisnosti od regiona. Tako na primer, u Nemačkoj nije potrebna bilo kakva dozvola za rukovanje letelicom ukoliko njena masa ne prelazi $5 \mathrm{~kg}$, pri letu u kome udaljenost letelice od daljinskog upravljača nije veća od 1,5km. [11].

U Americi je za upravljanje ovakvim letelicama potrebno posebno odobrenje prilikom svakog poletanja. Takođe se zahteva da svako lice koje upravlja letelicom poseduje pilotsku dozvolu za upravljanje određenim tipom bespilotnih letelica. Slično Americi, u Kanadi je takođe potrebno posebno odobrenje koje se može dobiti usmeno od kontrole vazdušnog saobraćaja kojoj pripada područje na kome se sprovodi let. Takođe, pored obobrenja za konkretan let, lice koje upravlja letelicom mora da prođe određenu vrstu obuke. U sklopu dozvole za upravljanje, obavezna je i uplata osiguranja koje pokriva slučajeve pada letelice, jer može dovesti do povređivanja ljudi, životinja kao i do materijalne štete nad objektima [12].

U Republici Srbiji u skladu sa članom 8. Konvencije o međunarodnom civilnom vazduhoplovstvu (Čikaška konvencija) nijedan vazduhoplov kojim se može upravljati bez pilota ne sme da preleće teritoriju Republike Srbije bez posebnog odobrenja ili suprotno uslovima iz tog odobrenja. Bespilotni vazduhoplovi se mogu koristiti u privredne, naučne, obrazovne, sportske i druge svrhe tako da ne ugrožavaju bezbednost vazdušnog saobraćaja [13]. Za eventualnu štetu koja je nastala usled korišćenja bespilotnih vazduhoplova je odgovorno lice koje koristi bespilotni vazduhoplov. Članom 1 pravilnika o bespilotnim vazduhoplovima definisano je da se bez ikakve dozvole na teritoriji Republike Srbije može upravljati jedino vazduhoplovima čija je operativna masa manja od $0.5 \mathrm{~kg}$, ako njihova brzina ne prelazi $20 \mathrm{~m} / \mathrm{s}$ i koji dostižu maksimalno do $15 \mathrm{~m}$ dužine leta i maksimalnu visinu do $10 \mathrm{~m}$. Sve ostale bespilotne letelice su podeljene u četiri kategorije prema tehničkim karakteristikama. Za svaku od kategorija definisan je 
set odobrenja i dozvola koje lice koje upravlja letelicom mora da ima prilikom upravljanja. Bespilotim letelicama svrstanim u sve četiri kategorije može se upravljati bez dozvole za poletanje izdate od strane Direktorata za civilno vazduhoplovstvo, isključivo u slučajevima kada se bespilotna letelica koristi samo danju, pri čemu sve vreme mora da bude u vidnom polju lica koje njome upravlja. Maksimalna dozvoljena visina leta bespilotne letelice u ovakvom slučaju je 100 m iznad tla. Maksimalna dozvoljena horizontalna udaljenost bespilotne letelice od lica koje upravlja bespilotnom letelicom je $500 \mathrm{~m}$. Takođe, bez obzira na kategoriju kao ni na odobrenje leta od strane Direktorata za civilno vazduhoplovstvo nije dozvoljeno korišćenje bespilotne letelice čija je operativna masa veća od $150 \mathrm{~kg}$, kao i bespilotne letelice čiji je let u potpunosti kontrolisan od strane računara koji se nalazi u letelici. Članom 12 pravilnika definisano je da lice koje upravlja bespilotnom letelicom koja se koristi u privredne svrhe, kao i lice koje upravlja bespilotnom letelicom kategorije 2, 3 i 4 može da bude samo punoletno lice koje je zdravstveno sposobno i koje je položilo proveru znanja iz predmeta vazduhoplovni propisi [14]. Članom 15 pravilnika definisano je da prilikom upravljanja bespilotnom letelicom lice koje upravlja letelicom mora kod sebe da ima uputstvo proizvođača za korišćenje bespilotne letelice, kao i original ili overenu kopiju odobrenja Direktorata za konkretnu letelicu, akt o prihvatanju izjave o osposobljenosti, kao i potvrdu o položenoj proveri znanja. U cilju vođenja pravilne evidencije o bespilotnim letelicama na teritoriji Republike Srbije sve bespilotne letelice koje se koriste u privredne svrhe, kao i bespilotne letelice kategorije 2, 3 i 4 koje se koriste u neprivredne svrhe, upisuju se u Evidenciju vazduhoplova [15]. Ukoliko se izvrši poređenje zakonskih regulativa Republike Srbije sa drugim zemljama, može se uočiti velika sličnost. Sličnost se ugleda kako u registraciji dronova, tako i u obaveznom poznavanju vazduhoplovnih propisa od strane operatera letelice. Takođe, prisutna su i poklapanja kada je upitanju udaljenost letelice od aerodroma, visina leta, kao i let u liniji vidljivosti.

\section{ZAKLJUČAK}

Primena dronova u poljoprivredi obuhvata različite oblasti. U zavisnosti od oblasti primene, zahtevanih funkcionalnosti i specifičnih potreba i uslova rada, vrši se odabir letelice koja će odgovoriti formiranim zahtevima. U procesu odabira letelice pored osnovnih karakteristika letelice po pitanju performansi leta, figuriraju i komponente poput skupa potrebnih senzora, opremljenosti kamerama i opremom za hemijsku zaštitu i prihranu. Trenutno, praktična primena dronova širi se znatno brže od većine industrija. Velike investicije kao i pravne regulative kojima je regulisana upotreba dronova utiču na brzinu razvoja ovih letelica i njihovog korišćenja u domenu poljoprivredne proizvodnje. Posmatrano sa stanovišta pravnih regulativa kojima se reguliše upotreba dronova, u pojednim zemljama evidentan je pomak u domenu kreiranja slabijih ograničenja, kako bi upotreba ovih letelica bila jednostavnija i konfornija.

Tehnologija na kojoj se bazira upotreba dronova u okviru poljoprivredne industrije čini poljoprivrednu proizvodnju jednom od visokotehnološki naprednih oblasti. Praktično, korišćenjem dronova prikupljeni podaci se obrađuju u realnom vremenu, čime se vrši aktivno procesiranje i donošenje odluka. Upotreba dronova i analize podataka imaju veliki potencijal pružanja podrške u rešavanju nekih od najozbiljnijih problema sa kojima se suočava poljoprivredna proizvodnja. Takođe, prednosti ovakve upotrebe mogu se smatrati višestrukim.

\section{LITERATURA}

[1] Q. Zhang, "Precision agriculture technology for crop farming", Taylor \& Francis Group, 2016.

[2] G. Sylvester, "E-Agriculture in action: drones for agriculture", Food and Agriculture Organization of the United Nations and International Telecommunication Union, Bangkok, 2018.

[3] A. Barrientos, J. Colorado, J. D. Cerro, A. Martinez, C. Rossi, D. Sanz, and J. Valente, "Aerial remote sensing in agriculture: A practical approach to area coverage and path planning for fleets of mini aerial robots". Journal of Field Robotics, Vol. 28, Num. 5, pp. 667-689, 2011.

[4] C. Zhang, and K. Kovacs, "The application of small unmanned aerial systems for precision agriculture: a review". Precision agriculture, Vol. 13, Num 6, pp. 693-712, 2012.

[5] Y. Lan, Y. Huang, D.E. Martin, and W. C. Hoffmann, "Development of an airborne remote sensing system for crop pest management: System integration and verification". Transactions of the ASABE, Vol. 25, pp. 607-615, 2009.

[6] R. Wadke, "Insurers now deploy drones to check claims by farmers." The Hindu-Business Line - Agri Bussiness, January 2018. Retrieved 20.01.2019., from: https://www.thehindubusinessline.com/ economy/agri-business/insurers-deploy-dronesto-check-claims-by-farmers/article9583909.ece 
[7] A. Nixon, "Best Drones For Agriculture 2019: The Ultimate Buyer's Guide“, February 2019, Retrieved 18.03.2019., from: http://bestdroneforthejob.com/ drone-buying-guides/ agriculture-drone-buyersguide/

[8] Livona, "Ekonomični bespilotni aerofotogrametrijski sistem“, Preuzeto 20.12.2018., sa: http://www. livona.rs/wp-content/uploads/Livona_BAS_201516.pdf

[9] DJI News, "DJI Raises Bar For Aerial Imaging With Two New Flying Cameras", Retrieved 08.01.2017., from: https://www.dji.com/newsroom/news/dji-raisesbar-for-aerial-imaging-with-two-new-flying-cameras

[10] Bejing TT Aviation Technology, "M6E-X", Retrieved 20.02.2019. from https://www.ttaviation. org/pro/m6e-x

[11] J. S. Aber, I. Marzolff, J. B. and Ries, "Smallformat aerial photography: principles, techniques and geoscience applications“, Elsevier, Oxford, 2010.
[12] P. J. Hardin, and R.R Jensen, "Small-scale unmanned aerial vehicles in environmental remote sensing: Challenges and opportunities", GIScience \& Remote Sensing, Vol. 48, pp. 99-111, 2011.

[13] G. Lewis, "Evaluating the use of a low-cost unmanned aerial vehicle platform in acquiring digital imagery for emergency response“, In Geomatics solutions for disaster management, Springer, Berlin Heidelberg, pp. 117-133, 2007.

[14] M. Čizmarov, "Pravilnik o bespilotnim vazduhoplovima“, Direktorat civilnog vazduhoplovstva Republike Srbije, 2015.

[15] M. Ilić, Ž. Spalević, P. Spalević, M. Veinović, A. Stojnev, "Informatičko pravna karakterizacija upotrebe dronova u poljoprivredi“, Zbornik radova YU INFO, Društvo za informacione sisteme i računarske mreže, pp. 121-126, 2017. 